\title{
Quinidine catalyzed reaction between 4-formyloxyazetidin-2-one and some thiophenols, thiols and alcohols
}

\author{
Anna Koziol, ${ }^{a}$ Elisa Altieri, ${ }^{\text {b }}$ Bartlomiej Furman, ${ }^{a}$ Jolanta Solecka, ${ }^{c}$ and Marek \\ Chmielewski ${ }^{\text {a } *}$ \\ ${ }^{a}$ Institute of Organic Chemistry, Polish Academy of Sciences, Kasprzaka 44/52, 01-224 Warsaw, \\ Poland \\ ${ }^{b}$ Dip. di Chimica Organica e Biologica, Università, Vill. S. Agata, I 98166 Messina, Italy \\ ${ }^{c}$ National Institute of Public Health-National Institute of Hygiene, Chocimska 24, 00-791 \\ Warsaw, Poland \\ E-mail : chmiel@icho.edu.pl
}

Dedicated to Professor Siegfried Blechert in occasion of his $65^{\text {th }}$ birthday

\begin{abstract}
Readily available 4-formyloxyazetidinone was enantioselectively transformed into 4-substituted azetidinones upon treatment with 0.1 equiv. of the cinchona alkaloid (quinidine) in toluene via intermolecular nucleophilic trapping of the $N$-acylimine intermediate by mercapto-, or hydroxymoieties of thiophenols, thiols, phenols and alcohols. Additionally, biological activity tests were performed on the newly synthesized $\beta$-lactams.
\end{abstract}

Keywords: Chiral Lewis base, chiral Lewis acid, enantioselective synthesis, $\beta$-lactams

\section{Introduction}

Compounds containing a $\beta$-lactam core are synthetic targets of great importance for academic and industrial laboratories owning to their various biological activities such as antibacterial, ${ }^{1}$ inhibition of enzymes like HLE, ${ }^{2}$ thrombin, ${ }^{3}$ human cytomegalovirus protease, ${ }^{4}$ or highly specific cholesterol inhibitors. ${ }^{5}$ The synthesis of $\beta$-lactam compounds can be achieved in two ways: by transformation of readily available natural products, or by total synthesis. ${ }^{6}$ In the latter case, the method of formation of the $\beta$-lactam ring together with control of the stereogenic centers at C-3 and C-4 of the azetidin-2-one ring is crucial for the success of the synthesis.

Recently, we have demonstrated that a 4-acyloxy substituent in the azetidin-2-one ring could be replaced by phenols in both chiral base and chiral acid catalyzed reactions leading to 
enantiomerically enhanced products. In particular, quinidine effectively catalysed the reaction between $\mathbf{1}$ and salicyl aldehydes $\mathbf{2}$ providing the corresponding 3,4-benzo-2-hydroxy-5oxacephams 5 (Scheme 1). ${ }^{7}$ The key step of this cascade reaction is based on the chiral Lewis base (quinidine) mediated, enantioselective intermolecular alkylation of the phenol hydroxy group with neutral 1,4-dehydroazetidin-2-one $\mathbf{3}$ which is followed by formation of the cyclic hemiacetal 5. ${ }^{8}$ Other phenols react with 1 with similar enantioselectivity providing the corresponding 4-aryloxyazetidinones.

This methodology enables the formation of a new stereogenic centre at C-4 of the azetidin-2-one ring with an enantioselectivity of up to $50 \%$ ee and a good yield $70 \%-90 \%$. The absolute configuration of $\mathbf{5}$ was assigned on the basis of the $\mathrm{CD}$ spectra and depends on the cinchona alkaloid used. $^{7}$

We have also described a chiral Lewis acid mediated intramolecular alkylation of the phenol hydroxy group by the acyliminium ion $\mathbf{8}$ generated from the corresponding 4-formyloxy- $\mathrm{N}$ substituted-azetidinones $6{ }^{9}$ This reaction, however, always requires an equimolar amount of the acid promoter 7 and proceeds in a low yield but high asymmetric induction as a kinetic resolution of the primary formed racemic 3,4-benzo-5-oxacepham 9-rac. Contrary to the base catalyzed reactions, Lewis acid promoted intermolecular reactions between $\mathbf{1}$ and phenols proceed in low yield and low asymmetric induction.

So far, we have reported asymmetric reactions concerned with the formation of 3,4-benzo-5oxacepham skeletons or 4-aryloxyazetidinones. Examination of whether other nucleophiles e.g thiophenols, thiols, or alcohols, can be applied in similar asymmetric processes is a logical consequence of our previous investigations. Formation of enantiomerically enriched 4substituted azetidinones would open an access to interesting monocyclic $\beta$-lactams, or after proper transformations, to a variety of clavams, penams and cephams. 


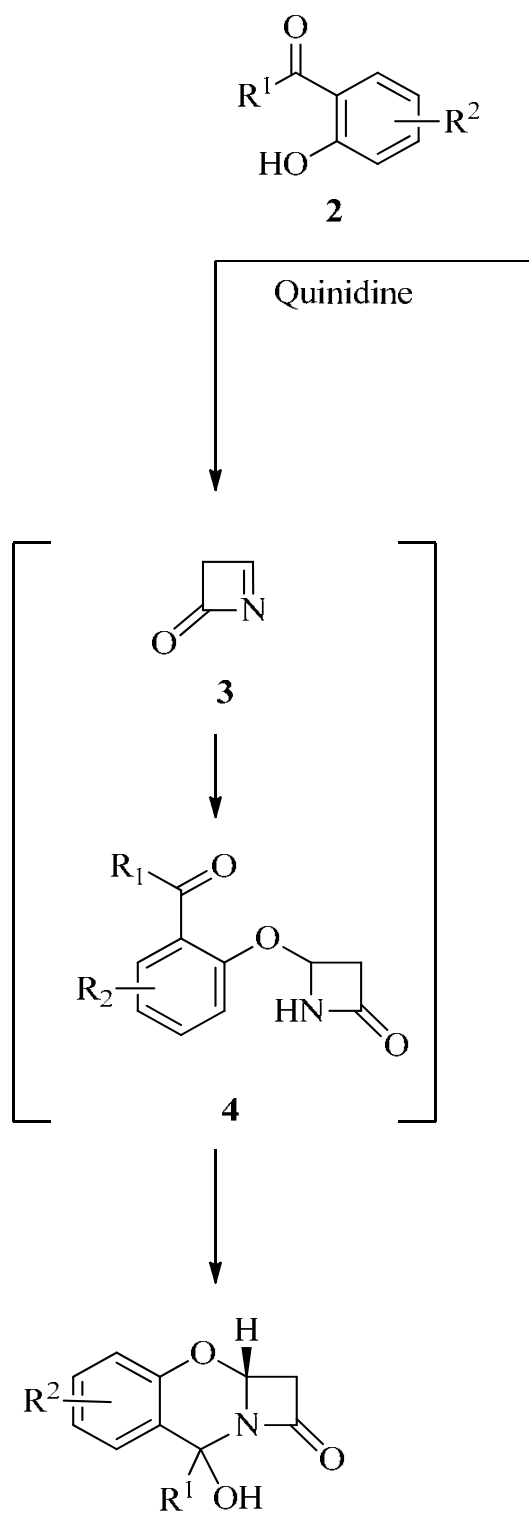

$5 \mathrm{R}^{\mathrm{I}}=\mathrm{H}, \mathrm{Me}, \mathrm{Ph}, \mathrm{R}^{\mathrm{l}}=\mathrm{H}, \mathrm{OMe}, \mathrm{OH}, \mathrm{Br}$ yields up to $90 \%$ up to $50 \%$ ee
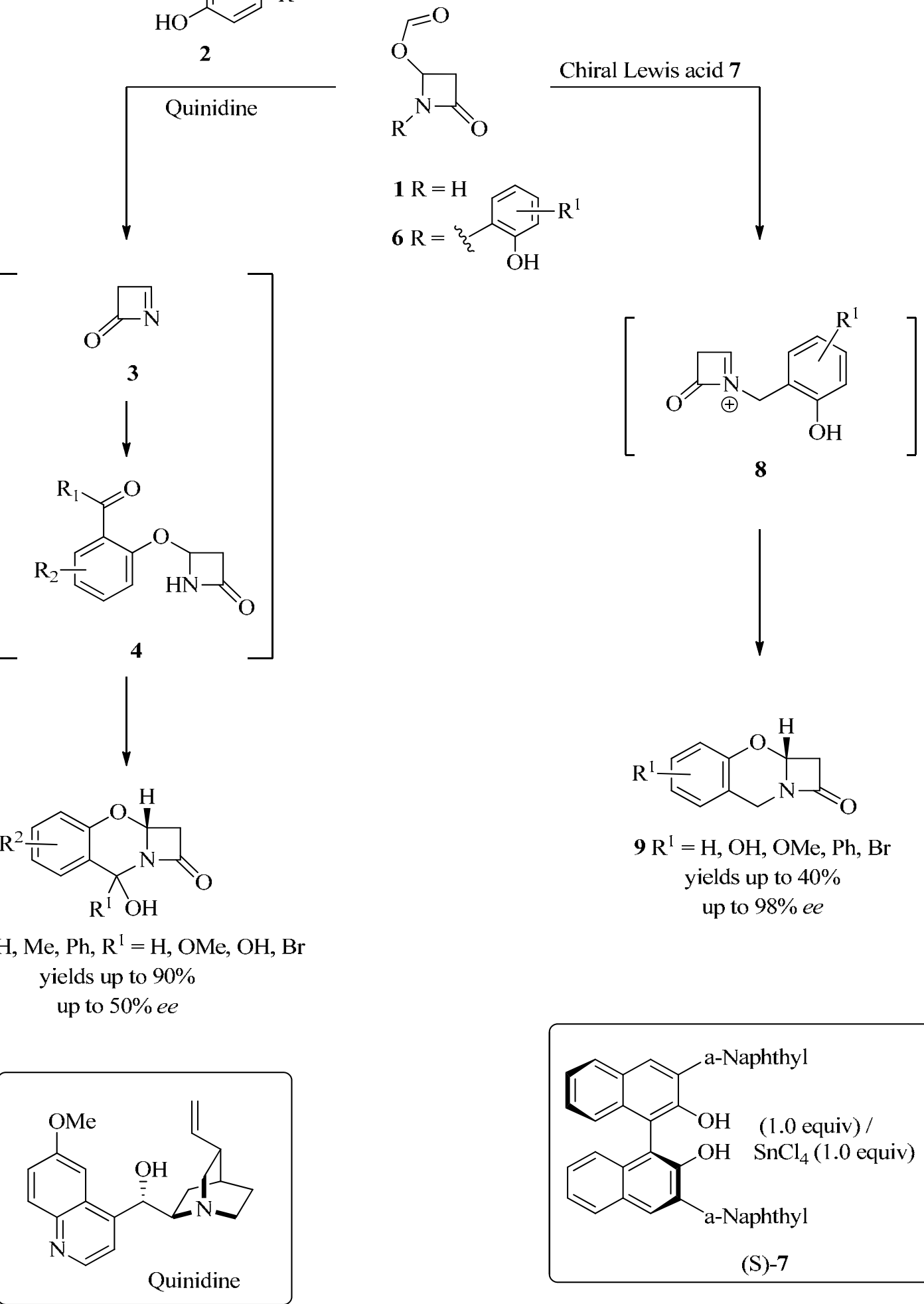

$9 \mathrm{R}^{\mathrm{I}}=\mathrm{H}, \mathrm{OH}, \mathrm{OMe}, \mathrm{Ph}, \mathrm{Br}$ yields up to $40 \%$ up to $98 \%$ ee

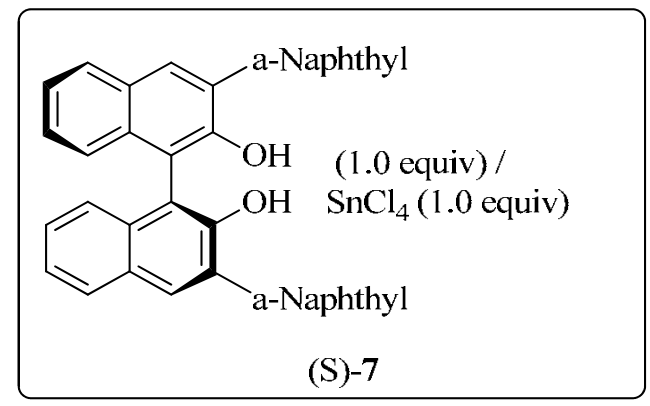

Scheme 1. Synthetic strategy. 


\section{Results and Discussion}

It was of interest to check whether cinchona alkaloids would catalyze the nucleophilic substitution at C-4 of the azetidin-2-one ring involving, more nucleophilic than oxygen congeners, thiophenols. 4-Formyloxyazetidin-2-one 1 was prepared by the ozonolysis of 4vinyloxyazetidin-2-one at $-78{ }^{\circ} \mathrm{C}$ in $\mathrm{CH}_{2} \mathrm{Cl}_{2}$, followed by reductive workup with dimethyl sulfide. High yields, and reproducibility of ozonolysis was achieved by the inclusion of a small amount of ozonizable dye (Sudan red 7B) as an internal standard, which indicated the reaction end point. ${ }^{10}$ The results of the experiments performed under conditions found optimal for the corresponding phenols are shown in (Table 1).

Table 1. Quinidine-catalyzed nucleophilic substitution with thiols $\mathbf{1 0}$

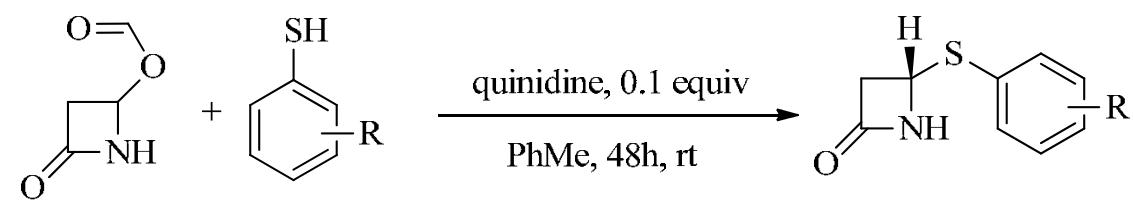
$1,1.0$ equiv
10, 1.1 equiv
11

\begin{tabular}{cccccc}
\hline Entry & Thiol & $\mathrm{R}$ & Product & ${\text { Yield }[\%]^{\mathrm{a}}}^{\mathrm{ee}[\%]^{\mathrm{b}}}$ \\
\hline 1 & $\mathbf{1 0 a}$ & $\mathrm{H}$ & $\mathbf{1 1 a}$ & 84 & 42 \\
2 & $\mathbf{1 0 b}$ & $2-\mathrm{Me}$ & $\mathbf{1 1 b}$ & 89 & 49 \\
3 & $\mathbf{1 0 c}$ & $4-\mathrm{OH}$ & $\mathbf{1 1 c}$ & 95 & 11 \\
4 & $\mathbf{1 0 d}$ & $4-\mathrm{OMe}$ & $\mathbf{1 1 d}$ & 75 & 34 \\
5 & $\mathbf{1 0 e}$ & $4-\mathrm{Br}$ & $\mathbf{1 1 e}$ & 95 & 34 \\
\hline
\end{tabular}

${ }^{\mathrm{a}}$ Isolated yield determined after flash chromatography on $\mathrm{SiO}_{2}$. Reaction was carried out until disappearance of substrate 1 (TLC monitored).

${ }^{\mathrm{b}}$ The enantiomeric excess was determined by chiral HPLC.

After a few initial attempts we found that the reaction of 4-formyloxyazetidin-2-one 1 with the thiophenols 10a-e, was most effective in the presence of a catalytic amount ( 0.1 mol. equiv.) of quinidine 3, in toluene at room temperature. As shown in Table 1, the enantiomeric excess, as well as the product's yield depended on the nature of the substituent in the thiophenol ring. In all cases, however, good chemical yields and moderate enantioselectivities of 4-arylthioazetidin-2ones 11a-e were observed.

The scope of nucleophiles was then extended to thiosalicylaldehyde 12. Under the same conditions, azetidinone $\mathbf{1}$ underwent condensation with 12 to provide 3,4-benzo-2- 
hydroxycepham 13 in $85 \%$ yield, with $38 \%$ ee (Scheme 2). The selectivity in the formation of 13 was similar to that found for reaction of 2 with salicylaldehyde. ${ }^{7}$

The experiments on cinchonine catalyzed substitutions testify that the switch from the oxygen nucleophile to the sulfur analog does not affect the enantioselectivity of the process. This might suggest that the elimination-addition mechanism of the first step is the same for both nucleophiles. In the case of thiosalicylaldehyde 12, the second step leading to the ring closure is under thermodynamic control and consequently leads to the exo location of the hemiacetal hydroxyl group.

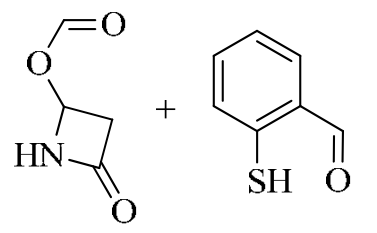

$1,1.0$ equiv.

12, 1.1 equiv

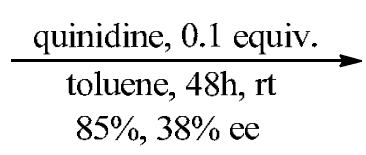

$85 \%, 38 \%$ ee

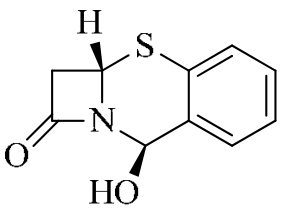

13

Scheme 2. Quinidine-catalyzed nucleophilic substitution with $o$-thiosalicylaldehyde $\mathbf{1 2}$.

Subsequently we decided to examine whether aliphatic alcohols and thiols would be proper substrates in the same nucleophilic substitution processes. First experiments showed that the products obtained 16/17 were volatile and therefore the yield of the reaction and the proportions of the enantiomers by HPLC were hard to be correctly assign. We found that in most cases direct benzylation of the nitrogen atom in 16/17 leading to 18/19 allowed us to determine the yield and enantiomeric excess of the reaction (Scheme 3). Independent experiments performed on 4benzyloxyazetidin-2-one 16c showed that $N$-benzylation is almost a quantitative process which does not affect the enantioselectivity of the nucleophilic substitution.

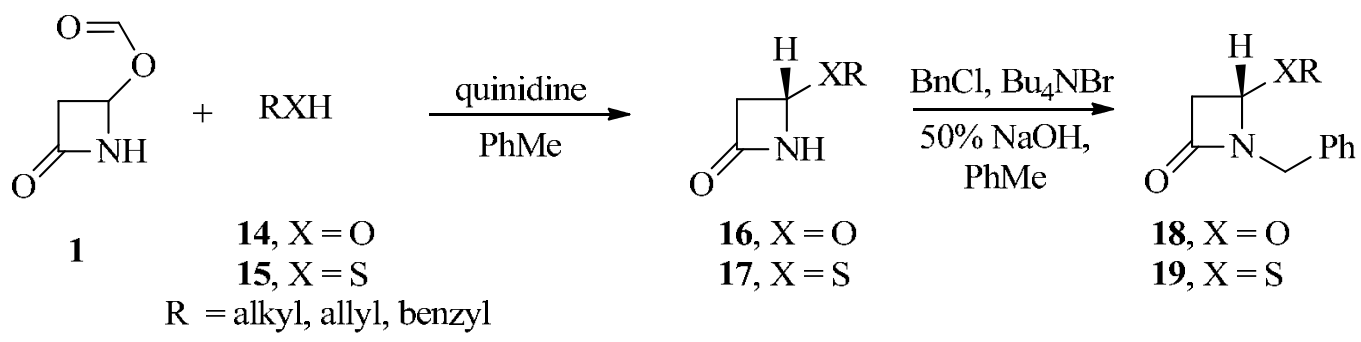

Scheme 3. Synthesis of $N$-benzylated 4-substituted azetidin-2-ones $\mathbf{1 8}$ and 19.

As has been demonstrated recently, the reaction between phenols and 4-formyloxyazetidin-2one $\mathbf{1}$ in the presence of a catalytic amount of quinidine proceeds in good yield and moderate enantioselectivity to afford the corresponding 4-aryloxyazetidin-2-ones. ${ }^{7}$ Different results were noticed when aliphatic alcohols or mercaptans were applied in the same reaction (Table 2, 3). In the case of aliphatic alcohols $\mathbf{1 4}$ an equimolar amount of quinidine was required to obtain full 
conversion of $\mathbf{1}$. An excess of the nucleophile 14 should also be raised from 1.5 to 3 equivalents (Table 2). The results obtained are modest and show a good yield only for benzyl alcohol, whereas the enantioselectivities are low for all nucleophiles.

Table 2. Quinidine promoted nucleophilic substitution with alcohols 14a-f

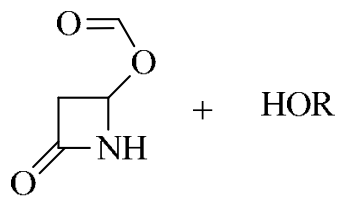

1, 1 equiv. 14a-f, 3 equiv. i) 1 equiv. quinidine
PhMe, $\mathrm{rt}, 48 \mathrm{~h}$

ii) 1.5 equiv. $\mathrm{BnCl}, 1$ equiv. TEB $A B r, 50 \%$

$\mathrm{NaOH}, \mathrm{PhMe}, \mathrm{rt}, 30$ min

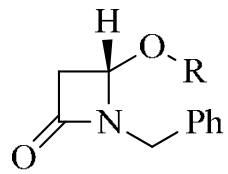

18a-f

\begin{tabular}{cccccc}
\hline Entry & Substrate & $\mathrm{R}$ & Product & ${\text { Yield }[\%]^{\mathrm{a}}}$ & $e e[\%]^{\mathrm{b}}$ \\
\hline 1 & $\mathbf{1 4 a}$ & $\mathrm{CH}_{2}=\mathrm{CHCH}$ & $\mathbf{1 8 a}$ & 15 & 10 \\
2 & $\mathbf{1 4 b}$ & $\mathrm{CH} \mathrm{CCH}_{2}$ & $\mathbf{1 8 b}$ & 30 & 12 \\
3 & $\mathbf{1 4 c}$ & $\mathrm{Ph} \mathrm{CH}_{2}$ & $\mathbf{1 8 c}$ & 77 & 4 \\
4 & $\mathbf{1 4 d}$ & $\mathrm{Et}$ & $\mathbf{1 8 d}$ & 12 & $\mathrm{nd}$ \\
5 & $\mathbf{1 4 e}$ & $i-\mathrm{Pr}$ & $\mathbf{1 8 d}$ & 15 & 11 \\
6 & $\mathbf{1 4 f}$ & $t$-Bu & $\mathbf{1 8 f}$ & 0 & - \\
\hline
\end{tabular}

as Isolated yield determined after flash chromatography on $\mathrm{SiO}_{2}$. Reaction was carried out until the disappearance of the substrate 1 (TLC monitored).

${ }^{\mathrm{b}}$ The enantiomeric excess was determined by chiral HPLC.

In contrast to aliphatic alcohols 14, analogous thiols 15 undergo reaction with 1 to provide the corresponding sulfides 19 under standard catalytic reaction conditions in good chemical yields and enantioselectivities similar to that observed for phenols (Table 3).

Comparison of the corresponding results of alcohols and thiols shows much better results for the latter. When $t$-butyl alcohol was used no reaction was observed (Table 2, entry 6), but its thio- congener gave an expected product in $65 \%$ yield and $12 \%$ ee (Table 3 , entry 3 ). The best result was obtained for triphenylmethyl thiol (Table 3. entry 4). It gave an excellent yield of 20 and $51 \%$ ee (Table 3 , entry 4 ). In this case, owing to high molecular weight, further benzylation of the nitrogen atom in order to assign enantioselectivity was not necessary. 
Table 3. Quinidine-catalyzed nucleophilic substitution with thioalcohols $\mathbf{1 5}$ a-d

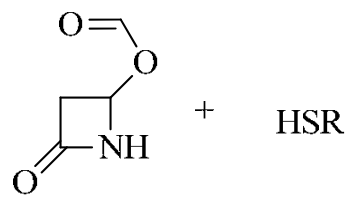

$1,1.0$ equiv.

$15,1.5$ equiv.

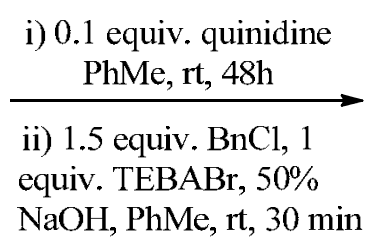

$\mathrm{NaOH}, \mathrm{PhMe}, \mathrm{rt}, 30 \mathrm{~min}$

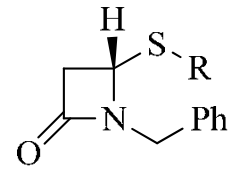

19a-c

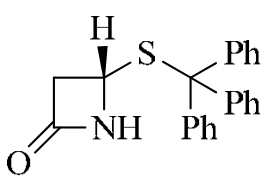

20

\begin{tabular}{cccccc}
\hline Entry & Substrate & $\mathrm{R}$ & Product & ${\text { Yield }[\%]^{\mathrm{a}}}$ & ee $[\%]^{\mathrm{b}}$ \\
\hline 1 & $\mathbf{1 5 a}$ & $\mathrm{CH}_{2}=\mathrm{CHCH}$ & $\mathbf{1 9 a}$ & 40 & 38 \\
2 & $\mathbf{1 5 b}$ & $\mathrm{PhCH}_{2}$ & $\mathbf{1 9 b}$ & 86 & 34 \\
3 & $\mathbf{1 5 c}$ & $t-\mathrm{Bu}$ & $\mathbf{1 9 c}$ & 65 & 12 \\
4 & $\mathbf{1 5 d}$ & $\mathrm{Ph}_{3} \mathrm{C}$ & $\mathbf{2 0}$ & 89 & 51 \\
\hline
\end{tabular}

${ }^{\mathrm{a}}$ Isolated yield determined after flash chromatography on $\mathrm{SiO}_{2}$. Reaction was carried out until the disappearance of the substrate 1 (TLC monitored).

${ }^{\mathrm{b}}$ The enantiomeric excess was determined by chiral HPLC.

In contrast to chiral base catalyzed nucleophilic substitution at C-4 of azetidinone 1, the intermolecular reaction promoted by chiral Lewis acid - equimolar mixture of $\mathrm{SnCl}_{4}$ and $(S)-\alpha$ di-naphthyl-BINOL 7 - proceeded in a different way for phenols and thiophenols. ${ }^{9}$ We found that the direct reaction between 1 and thiophenol 10a in the presence of the $\mathrm{BINOL} / \mathrm{SnCl}_{4}$ complex 7 provided the racemic compound 11a in low yield. Asymmetric degradation of the racemic 4-phenylthioazetidin-2-ones 11 gave better enantiomer selectivities. After $6 \mathrm{~h}$ 11a underwent destruction in $41 \%$ yield and $42 \%$ ee (Table 4 , entry 1 ). In comparison to phenols, nucleophilic substitution involving thiophenols is faster, whereas asymmetric degradation of the primary formed racemic compound is slower due to a more stable $\mathrm{N}, \mathrm{S}$-acetal then $\mathrm{N}, \mathrm{O}$-congener. The moderate asymmetric induction for the Lewis acid promoted kinetic resolution process may be also caused by a reversible process abstraction-addition of the thiophenoxy group which should lead to partial racemization of the product.

Chiral Lewis acid 7 catalyzed, asymmetric degradation of the racemic 3,4-benzocepham 22 after $6 \mathrm{~h}$ at $0{ }^{\circ} \mathrm{C}$ provided an enantiomerically enhanced compound in $48 \%$ yield and $46 \%$ ee (Scheme 4). The lower result of the kinetic resolution of 22 in comparision with 9 is caused by the same reasons as suggested for $\mathbf{1 1}$ and $\mathbf{2 1 .}$ 
Table 4. Chiral Lewis acid 7 promoted deracemization of 4-thioaryloxyazetidin-2-ones

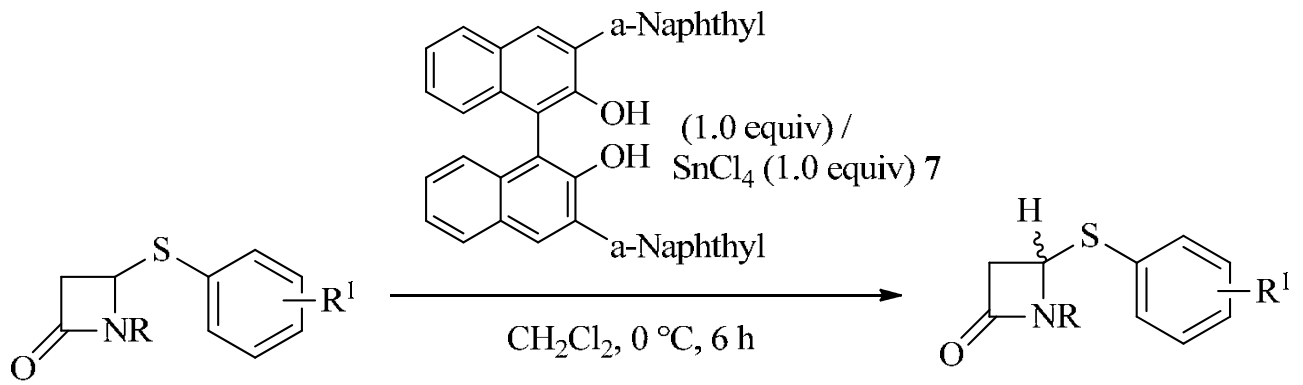

11: $\mathrm{R}=\mathrm{H}$

21: $\mathrm{R}=\mathrm{Bn}$

\begin{tabular}{ccccccc}
\hline Entry & Lewis acid 7 & $\mathrm{R}$ & $\mathrm{R}^{1}$ & Product & Yield [\%] $^{\mathrm{a}}$ & ee [\%] $^{\mathrm{b}}$ \\
\hline 1 & $R$ & $\mathrm{H}$ & $\mathrm{H}$ & $\mathbf{1 1 a}$ & 41 & $42(S)$ \\
2 & $R$ & $\mathrm{H}$ & $4-\mathrm{OMe}$ & $\mathbf{1 1 d}$ & 45 & $34(S)$ \\
3 & $S$ & $\mathrm{Bn}$ & $\mathrm{H}$ & $\mathbf{2 1 a}$ & 40 & $37(R)$ \\
4 & $S$ & $\mathrm{Bn}$ & $4-\mathrm{OMe}$ & $\mathbf{2 1 b}$ & 43 & $21(R)$ \\
\hline
\end{tabular}

${ }^{\mathrm{a}}$ Isolated yield determined after flash chromatography on $\mathrm{SiO}_{2}$.

${ }^{\mathrm{b}}$ The enantiomeric excess was determined by chiral HPLC.

Similar asymmetric degradation was performed for 5-oxacepham $\mathbf{2 3}$ obtained by us a few years ago. ${ }^{11}$ Under the same conditions ee was found to be only $22 \%$ (Scheme 4 ).<smiles>O=C1CC2Sc3ccccc3CN12</smiles>

22<smiles>C=C1COC2CC(=O)N2C1</smiles>

23

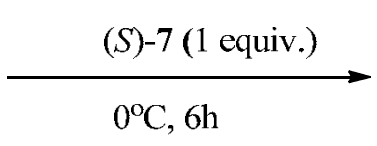

$(S)-7$ (1 equiv.)

$-78^{\circ} \mathrm{C}, 36 \mathrm{~h}$

$48 \%, 22 \%$ ee

Scheme 4. Chiral Lewis acid 7 promoted deracemization of cepham's congeners.

\section{Biological activity}

4-Thiophenoxy compounds 11a-e were tested for their biological activity. An inhibition of the DD-carboxypeptidase activity and, separately, an inhibition of $\beta$-lactamase were measured. ${ }^{12-13}$ 
Within the studied series, all of the tested azetidin-2-ones 11a-e showed a low activity towards DD-peptidase. Except 11b which showed the inhibition of $\beta$-lactamase class $\mathrm{A}$ activity, expressed by the value of $2.5 \times 10^{-2}$, other compounds do not showed any activity as inhibitors of the $\beta$-lactamase.

\section{Conclusions}

In conclusion, we report a simple approach to the asymmetric synthesis of 3,4-benzo-2-hydroxycephams, 4-thiophenoxyazetidin-2-ones and 4-alkoxyazetidin-2-ones. The key step of this method is based on the chiral Lewis base mediated, enantioselective, intermolecular alkylation of mercapto or hydroxyl groups by intermediately formed dehydro-azetidinone. It is important to note that the chiral Lewis base is used in catalytic amounts without effecting both the yield and enantioselectivity. The reactions proceed in similar yield and with similar selectivity for thiols and alcohols. This is in contrast with that previously described for the chiral Lewis acid mediated enantioselective alkylation of the phenol hydroxy group by the $N$-acyliminium ion generated from the 4-formyloxyazetidinone $\mathbf{1}$, which requires always an equimolar amount of the promoter and proceeds in low yield but high asymmetric induction as the intramolecular process, or in good yield but low asymmetric induction as the intermolecular process. Due to the higher stability of the $N, S$-acetal versus the $N, O$-one asymmetric degradations of 4-alkoxyazetidinones or 5-oxacephams proceed more readily.

\section{Experimental Section}

General. All reactions involving air- and moisture-sensitive materials were performed under an atmosphere of dry argon using dry solvents. Reagents were purchased from commercial suppliers and used without further purification, unless noted. Tetrahydrofuran was distilled from $\mathrm{Na}$ and bezophenon ketyl and dichloromethane were distilled from $\mathrm{CaH}_{2}$. All processes were performed until the disappearance of the starting material (TLC monitoring). Melting points were determinated using a hot-stage apparatus with a microscope and are uncorrected. The column chromatography was performed on Kiesel gel (230 - 400 mesh). Thin layer chromatography (TLC) was performed on aluminum sheets Silica Gel $60 \mathrm{~F}_{254}(20$ x 20 x 0.2). TLC spots were visualized in UV $(254 \mathrm{~nm})$ and by treatment by the solution of ceric acid. Routine NMR spectra were obtained at $500 \mathrm{MHz}$ for ${ }^{1} \mathrm{H} \mathrm{NMR}$ and $128 \mathrm{MHz}$ for ${ }^{13} \mathrm{C} \mathrm{NMR}$, using $\mathrm{CDCl}_{3}$ as a solvent and TMS as an integral reference $\left(\delta 0\right.$ for ${ }^{1} \mathrm{H}$ and $\left.\delta 0{ }^{13} \mathrm{C}\right)$. IR data were obtained with a FT-IR-1600-Perkin - Elmer spectrophotometer. High resolution mass spectra were recorded on anAMD 604 mass spectrometer (EI, $70 \mathrm{eV}$ ) and ESI-TOF Mariner spectrometer (Perspective Biosystem). The optical rotations were measured using JASCO J-1020 digital polarimeters. The high pressure liquid chromatography (HPLC) was performed using a 
Merck - Hitachi chromatograph with a L-2130 pump, diode array detector L-2450, analytical columns : Chiralpark ${ }^{\circledR}$ AD-H, Chiralcel ${ }^{\circledR} \mathrm{OD}-\mathrm{H}$ and OJ-H and hexane / $i$-propanole as solvents.

\section{Quinidine-catalyzed nucleophilic substitution with thiols (10) and (12)}

To a solution of 4-formyloxyazetidin-2-one 1 (30 mg, $0.26 \mathrm{mmol}, 1.0$ equiv.) and thiol 10, 12 ( $0.29 \mathrm{mmol}, 1.1$ equiv. $)$ in toluene $(5 \mathrm{~mL})$ at room temperature was added quinidine $(9 \mathrm{mg}, 0.1$ equiv.) under an argon atmosphere. The reaction mixture was stirred for $48 \mathrm{~h}$ till the disappearance of the starting material and diluted with water $(5 \mathrm{~mL})$. The aqueous phase was extracted with ether $(3 \times 10 \mathrm{~mL})$. The organic extracts were combined and dried over $\mathrm{Na}_{2} \mathrm{SO}_{4}$. The solution was filtered and the filtrate evaporated. The crude product was purified by column chromatography to yield $\mathbf{1 1}, 13$ respectively.

(4S)- 4-Phenylthioazetidin-2-one (11a). White solid, yield 84\%, 42\% ee, $39 \mathrm{mg}$ (0.22 mmol), m.p. $54-56^{\circ} \mathrm{C}, \quad$ IR $\left(v_{\max }, \mathrm{cm}^{-1}\right): 1778(\mathrm{C}=\mathrm{O}),[\alpha]_{\mathrm{D}}{ }^{26}=-110.7\left(\mathrm{c} 0.73, \mathrm{CHCl}_{3}\right) .{ }^{1} \mathrm{H}$ NMR $(500$ $\mathrm{MHz}, \mathrm{CDCl}_{3}$ ), $\delta_{\mathrm{H}} 2.89\left(\mathrm{ddd}, J=15.2,2.3,1.9 \mathrm{~Hz}, 1 \mathrm{H}, \mathrm{CH}_{2}\right), 3.36$ (ddd, $J=15.2,4.9,1.9 \mathrm{~Hz}$, $\left.1 \mathrm{H}, \mathrm{CH}_{2}\right), 5.00(\mathrm{dd}, J=4.9,2.3 \mathrm{~Hz}, 1 \mathrm{H}, \mathrm{CH}-\mathrm{S}), 6.38(\mathrm{~s}, 1 \mathrm{H}, \mathrm{NH}), 7.35$ (m, 3H, Ar), 7.45 (m, 2H, Ar). ${ }^{13} \mathrm{C}$ NMR $\left(125 \mathrm{MHz}, \mathrm{CDCl}_{3}\right), \delta_{\mathrm{C}} 45.4,54.2,128.6,129.4,131.4,133.5,165.8$. HR MS (TOF MS EI+) Calcd for $\mathrm{M}^{+} \mathrm{C}_{9} \mathrm{H}_{9} \mathrm{NOS}$ 179.0405, Found: 179.0396. HPLC [OD-H, hexane : $i$ propanole $=8: 2,0.5 \mathrm{~mL} / \mathrm{min}, t_{R}[R]=19.9$ (minor), $t_{R}[S]=23.8$ (major)].

(4S)-4-(o-Tolylthio)-azetidin-2-one (11b). White solid, yield 89\%, 49\% ee, $44 \mathrm{mg}$ (0.23 mmol), m.p. $62-64^{\circ} \mathrm{C}$, IR $\left(v_{\max }, \mathrm{cm}^{-1}\right): 1776(\mathrm{C}=\mathrm{O}),[\alpha]_{\mathrm{D}}{ }^{26}=-15.8\left(\mathrm{c} 1.0, \mathrm{CHCl}_{3}\right) .{ }^{1} \mathrm{H}$ NMR $(500 \mathrm{MHz}$, $\left.\mathrm{CDCl}_{3}\right) \delta_{\mathrm{H}} 2.44\left(\mathrm{~s}, 3 \mathrm{H}, \mathrm{CH}_{3}\right), 2.93\left(\mathrm{ddd}, J=15.2,2.3,1.9 \mathrm{~Hz}, 1 \mathrm{H}, \mathrm{CH}_{2}\right), 3.45(\mathrm{ddd}, J=15.2,4.9$, $1.9 \mathrm{~Hz}, 1 \mathrm{H}, \mathrm{CH}_{2}$ ), 4.99 (dd, $\left.J=4.9,2.3 \mathrm{~Hz}, 1 \mathrm{H}, \mathrm{CH}-\mathrm{S}\right), 6.25$ (s, 1H, NH), 7.19 (m, 1H, Ar), 7.25 (m $J=2 \mathrm{H}, \mathrm{Ar}), 7.37$ (m, 1H, Ar). ${ }^{13} \mathrm{C}$ NMR $\left(125 \mathrm{MHz}, \mathrm{CDCl}_{3}\right) \delta_{\mathrm{C}} 20.9,45.6,53.7,126.8,128.5$, 130.8, 131.4, 132.9, 140.5, 165.8. HR MS (TOF MS E+) Calcd for $\mathrm{M}^{+} \mathrm{C}_{10} \mathrm{H}_{11} \mathrm{NOS}$ 193.0561, Found: 193.0569. HPLC [OD-H, hexane : $i$-propanole $=8: 2,0.5 \mathrm{~mL} / \mathrm{min}, t_{R}[R]=17.0$ (minor), $t_{R}[S]=22.4$ (major) $]$.

(4S)-4-(4'-Hydroxyphenylthio)-azetidin-2-one (11c). White solid, yield 95\%, 11\% ee, $48 \mathrm{mg}$ $(0.25 \mathrm{mmol})$, m.p. $110-112^{\circ} \mathrm{C}$, IR $\left(v_{\max }, \mathrm{cm}^{-1}\right): 1788(\mathrm{C}=\mathrm{O}),[\alpha]_{\mathrm{D}}{ }^{26}=-1.8(\mathrm{c} 0.50, \mathrm{MeOH}) .{ }^{1} \mathrm{H}$ NMR $\left(500 \mathrm{MHz}, \mathrm{CD}_{3} \mathrm{OD}\right) \delta_{\mathrm{H}} 2.69\left(\mathrm{~d}, J=15.2,2.1 \mathrm{~Hz}, 1 \mathrm{H}, \mathrm{CH}_{2}\right), 3.22(\mathrm{dd}, J=15.2,4.8 \mathrm{~Hz}, 1 \mathrm{H}$, $\mathrm{CH}_{2}$ ), 4.87 (dd, $\left.J=4.8,2.1 \mathrm{~Hz}, 1 \mathrm{H}, \mathrm{CH}-\mathrm{S}\right), 6.80$ (d, $\left.J=8.8 \mathrm{~Hz}, 2 \mathrm{H}, \mathrm{Ar}\right), 7.37$ (d, $J=8.8 \mathrm{~Hz}, 2 \mathrm{H}$, $\mathrm{Ar}) .{ }^{13} \mathrm{C} \mathrm{NMR}\left(\mathrm{CD}_{3} \mathrm{OD}\right) \delta_{\mathrm{C}} 44.8,55.5,117.2,120.3,138.3,159.9,169.2$. HR MS (ESI) Calcd for $[\mathrm{M}+\mathrm{Na}]^{+} \mathrm{C}_{9} \mathrm{H}_{8} \mathrm{NO}_{2} \mathrm{NaS}$ 218.0246, Found: 218.0242. HPLC [OD-H, hexane : $i$-propanole $=8$ : $2,0.5 \mathrm{~mL} / \mathrm{min}, t_{R}[R]=21.3$ (minor), $t_{R}[S]=23.6$ (major).

(4S)-4-(p-Methoxyphenylthio)-azetidin-2-one (11d). White solid, yield 75\%, 34\% ee, $40 \mathrm{mg}$ (0.19 mmol), m.p. $71-73^{\circ} \mathrm{C}$, IR $\left(v_{\max }, \mathrm{cm}^{-1}\right): 1776(\mathrm{C}=\mathrm{O}),[\alpha]_{\mathrm{D}}{ }^{26}=-24.8\left(\mathrm{c} 0.755, \mathrm{CHCl}_{3}\right) .{ }^{1} \mathrm{H}$ NMR $\left(500 \mathrm{MHz}, \mathrm{CDCl}_{3}\right) \delta_{\mathrm{H}} 2.82\left(\mathrm{ddd}, J=15.2,2.2,1.6 \mathrm{~Hz}, 1 \mathrm{H}, \mathrm{CH}_{2}\right), 3.29$ (ddd, $J=15.2,4.9$, $1.6 \mathrm{~Hz}, 1 \mathrm{H}, \mathrm{CH}_{2}$ ), 3,81 (s, 3H, $\left.\mathrm{CH}_{3}\right), 4.88$ (dd, $\left.J=4.9,2.2 \mathrm{~Hz}, 1 \mathrm{H}, \mathrm{CH}-\mathrm{S}\right), 6.11$ (s, $\left.1 \mathrm{H}, \mathrm{NH}\right)$, $6.89(\mathrm{~d}, J=8.8 \mathrm{~Hz}, 2 \mathrm{H}, \mathrm{Ar}), 7.43(\mathrm{~d}, J=8.8 \mathrm{~Hz}, 2 \mathrm{H}, \mathrm{Ar}) .{ }^{13} \mathrm{C} \mathrm{NMR}\left(\mathrm{CDCl}_{3}\right) \delta_{\mathrm{C}} 44.9,54.7,55.4$, 114.9, 120.7, 136.7, 160.7, 165.7. HR MS (ESI) Calcd for $[\mathrm{M}+\mathrm{Na}]^{+} \mathrm{C}_{10} \mathrm{H}_{11} \mathrm{NO}_{2} \mathrm{NaS} 232.0402$, 
Found: 232.0398. HPLC [OD-H, hexane : $i$-propanole $=8: 2,0.5 \mathrm{~mL} / \mathrm{min}, t_{R}[R]=21.2$ (minor), $t_{R}[S]=25.4$ (major)].

(4S)-4-(4'-Bromophenylthio)-azetidin-2-one (11e). White solid, yield 95\%, 34\% ee, $66 \mathrm{mg}$ $(0.25 \mathrm{mmol})$, m.p. $107-109^{\circ} \mathrm{C}$, IR $\left(v_{\max }, \mathrm{cm}^{-1}\right): 1779(\mathrm{C}=\mathrm{O}),[\alpha]_{\mathrm{D}}{ }^{26}=-32.9\left(\mathrm{c} 0.96, \mathrm{CHCl}_{3}\right) .{ }^{1} \mathrm{H}$ NMR $\left(500 \mathrm{MHz}, \mathrm{CDCl}_{3}\right) \delta_{\mathrm{H}} 2.88\left(\mathrm{dm}, J=15.12,1 \mathrm{H}, \mathrm{CH}_{2}\right), 3.39(\mathrm{ddd}, J=15.2,4.9,2.0 \mathrm{~Hz}, 1 \mathrm{H}$, $\mathrm{CH}_{2}$ ), 4.98 (dd, $\left.J=4.9,2.3 \mathrm{~Hz}, 1 \mathrm{H}, \mathrm{CH}-\mathrm{S}\right), 6.29$ (s, 1H, NH), 7.32 (d, $\left.J=8.5 \mathrm{~Hz}, 2 \mathrm{H}, \mathrm{Ar}\right), 7.49$ $(\mathrm{d}, J=8.5 \mathrm{~Hz}, 2 \mathrm{H}, \mathrm{Ar}) .{ }^{13} \mathrm{C} \mathrm{NMR}\left(125 \mathrm{MHz}, \mathrm{CDCl}_{3}\right) \delta_{\mathrm{C}} 45.5,54.2,123.3,132.6,135.0,165.5$. HR MS (ESI) Calcd for $[\mathrm{M}+\mathrm{Na}]^{+} \mathrm{C}_{9} \mathrm{H}_{8} \mathrm{NONaSBr}$ 279.9402, Found: 279.9396. HPLC [OD-H hexane $: i$-propanole $=8: 2,0.5 \mathrm{~mL} / \mathrm{min}, t_{R}[R]=20.3$ (minor), $t_{R}[S]=21.9$ (major) $]$.

(2R, 6S)-3,4-Benzocepham (13). White solid, yield 85\%, 38\% ee, $46 \mathrm{mg}(0.22 \mathrm{mmol})$, m.p. 130$132^{\circ} \mathrm{C}$, IR $\left(v_{\max }, \mathrm{cm}^{-1}\right): 1778(\mathrm{C}=\mathrm{O}),[\alpha]_{\mathrm{D}}{ }^{26}=-25.8\left(\mathrm{c} 1.0, \mathrm{CHCl}_{3}\right) .{ }^{1} \mathrm{H} \mathrm{NMR}\left(500 \mathrm{MHz}, \mathrm{CDCl}_{3}\right)$ $\delta_{\mathrm{H}} 3.00\left(\mathrm{~d}, J=15.1 \mathrm{~Hz}, 1 \mathrm{H}, \mathrm{CH}_{2}\right), 3.351\left(\mathrm{dd}, J=15.1,4.3 \mathrm{~Hz}, 1 \mathrm{H}, \mathrm{CH}_{2}\right), 4.58(\mathrm{~s}, 1 \mathrm{H}, \mathrm{OH}), 4.93$ $(\mathrm{d}, J=4.3 \mathrm{~Hz}, 1 \mathrm{H}, \mathrm{CH}-\mathrm{S}), 6.04(\mathrm{~s}, 1 \mathrm{H}, \mathrm{CH}), 7.26(\mathrm{~m}, 3 \mathrm{H}, \mathrm{Ar}), 7.64$ (d, $J=5.4 \mathrm{~Hz}, 1 \mathrm{H}, \mathrm{Ar}) .{ }^{13} \mathrm{C}$ NMR $\left(125 \mathrm{MHz}, \mathrm{CDCl}_{3}\right) \delta_{\mathrm{C}} 45.8,45.9,69.7,126.2,128.6,129.3,129.5,129.9,130.1,165.7$. HR MS (ESI) Calcd for [M+Na] ${ }^{+} \mathrm{C}_{10} \mathrm{H}_{9} \mathrm{NO}_{2} \mathrm{NaS}$ 230.0246, Found: 230.0257. HPLC [OD-H, hexane : $i$-propanole $=8: 2,0.5 \mathrm{~mL} / \mathrm{min}, t_{R}[6 R]=16.8$ (minor), $t_{R}[6 S]=21.3$ (major)].

\section{Quinidine-catalyzed nucleophilic substitution with alcohols (14)}

To the solution of 4-formyloxyazetidin-2-one 1 (30 mg, $0.26 \mathrm{mmol}, 1.0$ equiv.) and alcohol 14 ( $0.78 \mathrm{mmol}, 3.0$ equiv.) in toluene $(5 \mathrm{~mL})$ at room temperature was added quinidine $(90 \mathrm{mg}, 1.0$ equiv.) under argon atmosphere. The reaction mixture was stirred for $48 \mathrm{~h}$ till disappearance of starting material and filtered through small layer of silica gel. The silica layer was washed with toluene $(2 \mathrm{~mL})$. Subsequently the filtrate containing 4-alkoxy-azetidin-2-one $\mathbf{1 6}$ was slowly added to solution of $50 \%$ aqueous $\mathrm{NaOH}(5 \mathrm{~mL})$, and $\mathrm{Bu}_{4} \mathrm{NBr}$ ( $84 \mathrm{mg}, 0.26 \mathrm{mmol}$, 1.0 equiv.) and benzyl chloride (135 $\mu \mathrm{L}, 1.17 \mathrm{mmol}, 4.5$ equiv.) in $1 \mathrm{~mL}$ of toluene. The reaction mixture was stirred for $30 \mathrm{~min}$ till disappearance of starting material and diluted with water $(10 \mathrm{~mL})$. The aqueous phase was extracted with ethyl acetate $(3 \times 15 \mathrm{~mL})$. The organic extracts were combined and dried over $\mathrm{MgSO}_{4}$. The solution was filtered and filtrate evaporated. The crude product was purified by column chromatography to yield 18 .

(4S)- $\boldsymbol{N}$-Benzyl-4-allyloxyazetidin-2-one (18a). Yellow oil, yield 15\%, $9 \mathrm{mg}$ (0.04 mmol), 10\% $e e, \operatorname{IR}\left(v_{\max }, \mathrm{cm}^{-1}\right): 1759(\mathrm{C}=\mathrm{O}),[\alpha]_{\mathrm{D}}{ }^{26}=-8.3\left(\mathrm{c} 0.5, \mathrm{CHCl}_{3}\right) .{ }^{1} \mathrm{H} \mathrm{NMR}\left(500 \mathrm{MHz}, \mathrm{CDCl}_{3}\right) \delta_{\mathrm{H}}$ $2.89\left(\mathrm{dm}, J=14.9 \mathrm{~Hz}, 1 \mathrm{H}, \mathrm{CH}_{2}\right), 3.05\left(\mathrm{dd}, J=14.9,3.8 \mathrm{~Hz}, 1 \mathrm{H}, \mathrm{CH}_{2}\right), 3.89$ (ddt, $J=12.7,5.7$, $\left.1.5 \mathrm{~Hz}, 1 \mathrm{H}, \mathrm{CH}_{2}-\mathrm{O}\right), 3.95$ (ddt, $\left.J=12.7,5.7,1.5 \mathrm{~Hz}, 1 \mathrm{H}, \mathrm{CH}_{2}-\mathrm{O}\right), 4.21$ (d, $J=15.2 \mathrm{~Hz}, 1 \mathrm{H}, \mathrm{CH}-$ $\mathrm{N}), 4.60\left(\mathrm{~d}, J=15.2 \mathrm{~Hz}, 1 \mathrm{H}, \mathrm{CH}_{2}-\mathrm{N}\right), 4.91\left(\mathrm{dd}, J=6.1,1.5 \mathrm{~Hz}, 1 \mathrm{H}, \mathrm{CH}_{2}=\right), 5.15(\mathrm{dm}, J=9.7$ $\left.\mathrm{Hz}, 1 \mathrm{H}, \mathrm{CH}_{2}=\right), 5.20(\mathrm{dd}, J=3.8,1.7 \mathrm{~Hz}, 1 \mathrm{H}, \mathrm{CH}-\mathrm{O}), 5.80(\mathrm{~m}, 1 \mathrm{H}, \mathrm{CH}=), 7.30$ (m, 3H, Ar), 7.35 (m, 2H, Ar). ${ }^{13} \mathrm{C} \mathrm{NMR}\left(\mathrm{CDCl}_{3}\right) \delta_{\mathrm{C}} 44.4,44.7,68.5,80.7,117.6,127.8,128.3,128.8,133.5$, 135.7, 165.9. HR MS (ESI) Calcd for $[\mathrm{M}+\mathrm{Na}]^{+} \mathrm{C}_{13} \mathrm{H}_{15} \mathrm{NO}_{2} \mathrm{Na}$ 240.0995, Found: 240.0987. HPLC $\left[\right.$ AD-H, hexane : $i$-propanole $=95: 5,0.5 \mathrm{~mL} / \mathrm{min}, t_{R}[R]=27.9$ (minor), $t_{R}[S]=30.1$ (major)]. 
(4S)- $\mathrm{N}$-Benzyl-4-propargyloxyazetidin-2-one (18b). Yellow oil, yield 30\%, 12\% ee, $17 \mathrm{mg}$ $(0.08 \mathrm{mmol}), \mathrm{IR}\left(v_{\max }, \mathrm{cm}^{-1}\right): 1762(\mathrm{C}=\mathrm{O}),[\alpha]_{\mathrm{D}}{ }^{26}=-11.5\left(\mathrm{c} 0.7, \mathrm{CHCl}_{3}\right) .{ }^{1} \mathrm{H} \mathrm{NMR}(500 \mathrm{MHz}$, $\left.\mathrm{CDCl}_{3}\right) \delta_{\mathrm{H}} 2.44(\mathrm{t}, J=2.4 \mathrm{~Hz}, 1 \mathrm{H}, \mathrm{CH}), 2.97\left(\mathrm{dd}, J=14.9,1.2 \mathrm{~Hz}, 1 \mathrm{H}, \mathrm{CH}_{2}\right), 3.09(\mathrm{dd}, J=14.9$, $3.7 \mathrm{~Hz}, 1 \mathrm{H}, \mathrm{CH}_{2}$ ), 4.05 (dd, $\left.J=16.0,2.4 \mathrm{~Hz}, 1 \mathrm{H}, \mathrm{CH}_{2}-\mathrm{C}\right), 4.11$ (dd, $J=16.0,2.4 \mathrm{~Hz}, 1 \mathrm{H}, \mathrm{CH}_{2}-$ C), $4.23\left(\mathrm{~d}, J=15.2 \mathrm{~Hz}, 1 \mathrm{H}, \mathrm{CH}_{2}-\mathrm{N}\right), 4.59\left(\mathrm{~d}, J=15.2 \mathrm{~Hz}, 1 \mathrm{H}, \mathrm{CH}_{2}-\mathrm{N}\right), 5.02(\mathrm{dd}, J=3.7,1.2$ $\mathrm{Hz}, 1 \mathrm{H}, \mathrm{CH}-\mathrm{O}), 7.30$ (m, 3H, Ar), 7.36 (m, 2H, Ar). ${ }^{13} \mathrm{C} \mathrm{NMR}\left(\mathrm{CDCl}_{3}\right) \delta_{\mathrm{C}} 44.6,44.7,55.2,75.3$, 78.8, 80.7, 127.8, 128.3, 128.8, 135.6, 165.8. HR MS (ESI) Calcd for $[\mathrm{M}+\mathrm{Na}]^{+} \mathrm{C}_{13} \mathrm{H}_{13} \mathrm{NO}_{2} \mathrm{Na}$ 238.0838, Found: 238.0845. HPLC [AD-H, hexane : $i$-propanole $=95: 5,0.7 \mathrm{~mL} / \mathrm{min}, t_{R}[R]=$ 34.2 (minor), $t_{R}[S]=35.8$ (major)].

(4S)- $N$-Benzyl-4-benzyloxyazetidin-2-one (18c). Yellow oil, yield 77\%, 4\% ee, $53 \mathrm{mg}(0.20$ mmol), IR $\left(v_{\max }, \mathrm{cm}^{-1}\right): 1758(\mathrm{C}=\mathrm{O}),[\alpha]_{\mathrm{D}}{ }^{26}=-4.0\left(\mathrm{c} 0.5, \mathrm{CHCl}_{3}\right) .{ }^{1} \mathrm{H}$ NMR $\left(500 \mathrm{MHz}, \mathrm{CDCl}_{3}\right)$ $\delta_{\mathrm{H}} 2.90\left(\mathrm{dm}, J=14.8 \mathrm{~Hz}, 1 \mathrm{H}, \mathrm{CH}_{2}\right), 3.04\left(\mathrm{dd}, J=14.8,3.8 \mathrm{~Hz}, 1 \mathrm{H}, \mathrm{CH}_{2}\right), 4.18(\mathrm{~d}, J=15.1 \mathrm{~Hz}$, $\left.1 \mathrm{H}, \mathrm{CH}_{2}-\mathrm{N}\right), 4.42\left(\mathrm{~d}, J=11.7 \mathrm{~Hz}, 1 \mathrm{H}, \mathrm{CH}_{2}-\mathrm{O}\right), 4.47\left(\mathrm{~d}, J=11.7 \mathrm{~Hz}, 1 \mathrm{H}, \mathrm{CH}_{2}-\mathrm{O}\right), 4.59(\mathrm{~d}, J=$ $15.1 \mathrm{~Hz}, 1 \mathrm{H}, \mathrm{CH}_{2}-\mathrm{N}$ ), 4.98 (dd, $\left.J=3.8,1.3 \mathrm{~Hz}, 1 \mathrm{H}, \mathrm{CH}-\mathrm{O}\right), 7.19$ (m, 2H, Ar), 7.30 (m, 8H, Ar). ${ }^{13} \mathrm{C}$ NMR $\left(\mathrm{CDCl}_{3}\right) \delta_{\mathrm{C}} 43.8,45.5,70.0,77.8,127.5,127.7,128.5,128.7,128.9,128.6,135.3$, 136.5, 166.3. HR MS (ESI) Calcd for $[\mathrm{M}+\mathrm{Na}]^{+} \mathrm{C}_{17} \mathrm{H}_{17} \mathrm{NO}_{2} \mathrm{Na} 290.1259$, Found: 290.1262. HPLC $\left[\mathrm{AD}-\mathrm{H}\right.$, hexane $: i$-propanole $=95: 5,0.7 \mathrm{~mL} / \mathrm{min}, t_{R}[S]=33.6$ (major), $t_{R}[R]=35.9$ (minor)].

(4S)- $\mathrm{N}$-Benzyl-4-ethoxyazetidin-2-one (18d). Yellow oil, Yield 12\%, ee not determinated, $6 \mathrm{mg}$ $(0.03 \mathrm{mmol}), \mathrm{IR}\left(v_{\max }, \mathrm{cm}^{-1}\right): 1758(\mathrm{C}=\mathrm{O}),[\alpha]_{\mathrm{D}}{ }^{26}=-5.2\left(\mathrm{c} 0.6, \mathrm{CHCl}_{3}\right) .{ }^{1} \mathrm{H} \mathrm{NMR}(500 \mathrm{MHz}$, $\left.\mathrm{CDCl}_{3}\right) \delta_{\mathrm{H}} 1.13\left(\mathrm{t}, J=6.9 \mathrm{~Hz}, 3 \mathrm{H}, \mathrm{CH}_{3}\right), 2.87\left(\mathrm{dm}, J=14.7 \mathrm{~Hz}, 1 \mathrm{H}, \mathrm{CH}_{2}\right), 3.03(\mathrm{dd}, J=14.7,3.8$ $\left.\mathrm{Hz}, 1 \mathrm{H}, \mathrm{CH}_{2}\right), 3.44\left(\mathrm{~m}, 2 \mathrm{H}, \mathrm{CH}_{2}\right), 4.20\left(\mathrm{~d}, J=15.2 \mathrm{~Hz}, 1 \mathrm{H}, \mathrm{CH}_{2}-\mathrm{N}\right), 4.59(\mathrm{~d}, J=15.2 \mathrm{~Hz}, 1 \mathrm{H}$, $\mathrm{CH}-\mathrm{N}), 4.86$ (dd, $\left.J=3.8,1.5 \mathrm{~Hz}, 1 \mathrm{H}, \mathrm{CH}_{2}-\mathrm{O}\right), 7.29$ (m, 3H, Ar), 7.34 (m, 2H, Ar). ${ }^{13} \mathrm{C}$ NMR $\left(\mathrm{CDCl}_{3}\right) \delta_{\mathrm{C}} 15.1,44.3,44.7,63.1,80.8,127.7,128.2,127.8,135.8,166.1$. HR MS (ESI) Calcd for $[\mathrm{M}+\mathrm{Na}]^{+} \mathrm{C}_{12} \mathrm{H}_{15} \mathrm{NO}_{2} \mathrm{Na} 228.0995$, Found: 228.1000 .

(4S)- $N$-Benzyl-4-isopropoxyazetidin-2-one (18e). Yellow oil, yield 15\%, 11\% ee, $9 \mathrm{mg}(0.04$ mmol), IR $\left(v_{\max }, \mathrm{cm}^{-1}\right): 1756(\mathrm{C}=\mathrm{O}),[\alpha]_{\mathrm{D}}{ }^{26}=-3.1\left(\mathrm{c} 0.71, \mathrm{CHCl}_{3}\right) .{ }^{1} \mathrm{H}$ NMR $\left(500 \mathrm{MHz}, \mathrm{CDCl}_{3}\right)$ $\delta_{\mathrm{H}} 1.09\left(\mathrm{~d}, J=6.1 \mathrm{~Hz}, 6 \mathrm{H}, 2 \mathrm{xCH}_{3}\right), 2.82\left(\mathrm{dm}, J=14.7 \mathrm{~Hz}, 1 \mathrm{H}, \mathrm{CH}_{2}\right), 3.07(\mathrm{dd}, J=14.7,3.7 \mathrm{~Hz}$, $1 \mathrm{H}, \mathrm{CH}_{2}$ ), 3.60 (septet, $\left.J=6.1 \mathrm{~Hz}, 1 \mathrm{H}, \mathrm{CH}-\left(\mathrm{CH}_{3}\right)_{2}\right), 4.13(\mathrm{~d}, J=15.2 \mathrm{~Hz}, 1 \mathrm{H}, \mathrm{CH}-\mathrm{N}), 4.85$ (dd, $J=3.7,1.2 \mathrm{~Hz}, 1 \mathrm{H}, \mathrm{CH}-\mathrm{O}), 7.29$ (m, 3H, Ar), 7.34 (m, 2H, Ar). ${ }^{13} \mathrm{C} \mathrm{NMR}\left(\mathrm{CDCl}_{3}\right) \delta_{\mathrm{C}} 22.5$, 22.7, 44.2, 45.9, 71.0, 79.5, 127.7, 128.3, 128.8, 135.8, 166.2. HR MS (ESI) Calcd for [M + Na] ${ }^{+}$ $\mathrm{C}_{13} \mathrm{H}_{17} \mathrm{NO}_{2} \mathrm{Na}$ 242.1152, Found: 242.1153. HPLC [AD-H, hexane : $i$-propanole $=95: 5,0.5$ $\mathrm{mL} / \mathrm{min}, t_{R}[R]=27.9$ (minor), $t_{R}[S]=30.1$ (major)].

\section{Quinidine-catalyzed nucleophilic substitution with thioalcohols (15)}

To the solution of 4-formyloxyazetidin-2-one (1) (30 mg, $0.26 \mathrm{mmol}, 1.0$ equiv.) and thioalcohol $15(0.39 \mathrm{mmol}, 1.5$ equiv. $)$ in toluene $(5 \mathrm{~mL})$ at room temperature was added quinidine $(90 \mathrm{mg}$, 1.0 equiv.) under argon atmosphere. The reaction mixture was stirred for $48 \mathrm{~h}$ till disappearance of starting material and filtered through small layer of silica gel. The silica layer was washed with toluene $(2 \mathrm{~mL})$. Subsequently the filtrate containing 4-thio-azetidin-2-one 17 was slowly 
added to solution of $50 \%$ aqueous $\mathrm{NaOH}(5 \mathrm{~mL})$, and $\mathrm{Bu} 4 \mathrm{NBr}$ ( $84 \mathrm{mg}, 0.26 \mathrm{mmol}, 1.0$ equiv.) and benzyl chloride ( $90 \mu \mathrm{L}, 0.78 \mathrm{mmol}, 3.0$ equiv.) in $1 \mathrm{~mL}$ of toluene. The reaction mixture was stirred for $30 \mathrm{~min}$ till disappearance of starting material and diluted with water $(10 \mathrm{~mL})$. The aqueous phase was extracted with ethyl acetate $(3 \times 15 \mathrm{~mL})$. The organic extracts were combined and dried over MgSO4. The solution was filtered and filtrate evaporated. The crude product was purified by column chromatography to yield 19 .

(4S)-4-Allylthio- $N$-benzylzetidin-2-one (19a). Yellow oil, yield 40\%, 38\% ee, $23 \mathrm{mg}(0.10$ mmol), IR ( $\left.v_{\max }, \mathrm{cm}^{-1}\right): 1755(\mathrm{C}=\mathrm{O}),[\alpha]_{\mathrm{D}}{ }^{26}=-20.3\left(\mathrm{c} 1.0, \mathrm{CHCl}_{3}\right) .{ }^{1} \mathrm{H}$ NMR $\left(500 \mathrm{MHz}, \mathrm{CDCl}_{3}\right)$ $\delta_{\mathrm{H}} 3.10\left(\mathrm{~m}, 3 \mathrm{H}, \mathrm{CH}_{2}, \mathrm{CH}_{2} \mathrm{~S}\right), 3.34\left(\mathrm{dd}, J=15.1,4.9 \mathrm{~Hz}, 1 \mathrm{H}, \mathrm{CH}_{2}\right), 4.07(\mathrm{~d}, J=15.3 \mathrm{~Hz}, 1 \mathrm{H}$, $\left.\mathrm{CH}_{2}-\mathrm{N}\right), 4.53$ (dd, $\left.J=4.9,2.2 \mathrm{~Hz}, 1 \mathrm{H}, \mathrm{CH}-\mathrm{S}\right), 4.70\left(\mathrm{~d}, J=15.3 \mathrm{~Hz}, 1 \mathrm{H}, \mathrm{CH}_{2}-\mathrm{N}\right), 4.90(\mathrm{dd}, J=$ 16.9, $\left.1.1 \mathrm{~Hz}, 1 \mathrm{H}, \mathrm{CH}_{2}=\right), 5.01\left(\mathrm{~d}, J=9.9 \mathrm{~Hz}, 1 \mathrm{H}, \mathrm{CH}_{2}=\right), 5.70(\mathrm{~m}, 1 \mathrm{H}, \mathrm{CH}=), 7.30$ (m, 3H, Ar), $7.35(\mathrm{~m}, 2 \mathrm{H}, \mathrm{Ar}) .{ }^{13} \mathrm{C} \mathrm{NMR}\left(\mathrm{CDCl}_{3}\right) \delta_{\mathrm{C}} 32.5,44.1,45.1,55.6,117.8,127.8,128.3,128.8,133.7$, 135.5, 165.4. HR MS (ESI) Calcd for $[\mathrm{M}+\mathrm{Na}]^{+} \mathrm{C}_{13} \mathrm{H}_{15} \mathrm{NONaS}$ 256.0767, Found: 256.0769. HPLC [AD-H, hexane : $i$-propanole $=95: 5,0.5 \mathrm{~mL} / \mathrm{min}, t_{R}[R]=34.2$ (minor), $t_{R}[S]=35.8$ (major)].

(4S)- $\mathrm{N}$-Benzyl-4-benzylthioazetidin-2-one (19b). Yellow oil, yield 86\%, 34\% ee, $62 \mathrm{mg}(0.22$ mmol), IR $\left(v_{\max }, \mathrm{cm}^{-1}\right): 1758(\mathrm{C}=\mathrm{O}),[\alpha]_{\mathrm{D}}{ }^{26}=-9.3\left(\mathrm{c} 1.0, \mathrm{CHCl}_{3}\right) .{ }^{1} \mathrm{H} \mathrm{NMR}\left(500 \mathrm{MHz}, \mathrm{CDCl}_{3}\right)$ $\delta_{\mathrm{H}} 2.93\left(\mathrm{dd}, J=15.1,2.2 \mathrm{~Hz}, 1 \mathrm{H}, \mathrm{CH}_{2}\right), 3.26\left(\mathrm{dd}, J=15.1,4.9 \mathrm{~Hz}, 1 \mathrm{H}, \mathrm{CH}_{2}\right), 3.58(\mathrm{~d}, J=13.5$ $\left.\mathrm{Hz}, 1 \mathrm{H}, \mathrm{CH}_{2}-\mathrm{S}\right), 3.67$ (d, $\left.J=13.5 \mathrm{~Hz}, 1 \mathrm{H}, \mathrm{CH}_{2}-\mathrm{S}\right), 3.94$ (d, $\left.J=15.3 \mathrm{~Hz}, 1 \mathrm{H}, \mathrm{CH}_{2}-\mathrm{N}\right), 4.50$ (dd, $J$ $=4.9,2.2 \mathrm{~Hz}, 1 \mathrm{H}, \mathrm{CH}-\mathrm{S}), 4.59\left(\mathrm{~d}, J=15.3 \mathrm{~Hz}, 1 \mathrm{H}, \mathrm{CH}_{2}-\mathrm{N}\right), 7.13$ (m, 2H, Ar), 7.30 (m, 8H, Ar). ${ }^{13} \mathrm{C}$ NMR $\left(\mathrm{CDCl}_{3}\right) \delta_{\mathrm{C}} 33.5,44.1,44.9,55.9,127.3,127.8,128.3,128.6,128.7,128.8,135.4$, 137.5, 165.3. HR MS (ESI) Calcd for $[\mathrm{M}+\mathrm{Na}]^{+} \mathrm{C}_{17} \mathrm{H}_{17} \mathrm{NONaS} 306.0923$, Found: 306.0921. HPLC [OD-H, hexane : $i$-propanole $=9: 1,0.5 \mathrm{~mL} / \mathrm{min}, t_{R}[R]=21.2$ (minor), $t_{R}[S]=25.4$ (major)].

(4S)- $N$-Benzyl-4-tert-butylthioazetidin-2-one (19c). Yellow oil, yield 65\%, 12\% ee, $37 \mathrm{mg}$ $(0.15 \mathrm{mmol}), \mathrm{IR}\left(v_{\max }, \mathrm{cm}^{-1}\right): 1754(\mathrm{C}=\mathrm{O}),[\alpha]_{\mathrm{D}}{ }^{26}=-3.4\left(\mathrm{c} 0.41, \mathrm{CHCl}_{3}\right) .{ }^{1} \mathrm{H} \mathrm{NMR}(500 \mathrm{MHz}$, $\left.\mathrm{CDCl}_{3}\right) \delta_{\mathrm{H}} 1.27\left(\mathrm{~s}, 9 \mathrm{H}, 3 \times \mathrm{xH}_{3}\right), 2.99\left(\mathrm{dm}, J=14.8 \mathrm{~Hz}, 1 \mathrm{H}, \mathrm{CH}_{2}\right), 3.46(\mathrm{dd}, J=14.8,4.7 \mathrm{~Hz}, 1 \mathrm{H}$, $\left.\mathrm{CH}_{2}\right), 4.00$ (d, $\left.J=15.4 \mathrm{~Hz}, 1 \mathrm{H}, \mathrm{CH}-\mathrm{N}\right), 4.59$ (dd, $\left.J=4.7,1.9 \mathrm{~Hz}, 1 \mathrm{H}, \mathrm{CH}-\mathrm{O}\right), 4.75$ (d, $J=15.4$ $\mathrm{Hz}, 1 \mathrm{H}, \mathrm{CH}-\mathrm{N}), 7.28$ (m, 3H, Ar), 7.35 (m, 2H, Ar). ${ }^{13} \mathrm{C} \mathrm{NMR}\left(\mathrm{CDCl}_{3}\right) \delta_{\mathrm{C}} 29.7,31.1,43.7,48.9$, 53.8, 127.6, 128.2, 128.7, 135.9, 165.8. HR MS (ESI) Calcd for $[\mathrm{M}+\mathrm{Na}]^{+} \mathrm{C}_{14} \mathrm{H}_{19} \mathrm{NONaS}$ 272.1080, Found: 272.1085. HPLC [AD-H, hexane $: i$-propanole $=95: 5,1.0 \mathrm{~mL} / \mathrm{min}, t_{R}[R]=$ 15.1 (major), $t_{R}[S]=19.8$ (minor) $]$.

\section{Quinidine-catalyzed nucleophilic substitution with thioalcohols (15)}

To the solution of 4-formyloxyazetidin-2-one 1 (30 mg, $0.26 \mathrm{mmol}, 1.0$ equiv.) and thioalcohol 15 ( $0.39 \mathrm{mmol}, 1.5$ equiv.) in toluene $(5 \mathrm{~mL})$ at room temperature was added quinidine $(90 \mathrm{mg}$, 1.0 equiv.) under argon atmosphere. The reaction mixture was stirred for $48 \mathrm{~h}$ till disappearance of starting material and diluted with water $(5 \mathrm{~mL})$. Aqueous phase was extracted with ether $(3 \times 10 \mathrm{~mL})$. The organic extracts were combined and dried over Na2SO4. The solution was 
filtered and filtrate evaporated. The crude product was purified by column chromatography (silica gel, 2:3 hexane/diethyl ether).

(4S)-4-Tritylthioazetidin-2-one (20). White solid, yield 89\%, 51\% ee, $80 \mathrm{mg}$ (0.23 mmol), m.p. $140-142^{\circ} \mathrm{C}$, IR $\left(v_{\max }, \mathrm{cm}^{-1}\right): 1772(\mathrm{C}=\mathrm{O}),[\alpha]_{\mathrm{D}}{ }^{26}=12.5\left(\mathrm{c} 1.0, \mathrm{CHCl}_{3}\right) .{ }^{1} \mathrm{H}$ NMR $(500 \mathrm{MHz}$, $\left.\mathrm{CDCl}_{3}\right) \delta_{\mathrm{H}} 2.88\left(\mathrm{ddd}, J=15.2,2.7,1.6 \mathrm{~Hz}, 1 \mathrm{H}, \mathrm{CH}_{2}\right), 3.27\left(\mathrm{ddd}, J=15.2,5.3,1.6 \mathrm{~Hz}, 1 \mathrm{H}, \mathrm{CH}_{2}\right.$ ), 4.44 (dd, $J=5.3,2.7 \mathrm{~Hz}, 1 \mathrm{H}, \mathrm{CH}-\mathrm{O}), 7.26$ (m, 3H, Ar), $7.32(\mathrm{~m}, 6 \mathrm{H}, \mathrm{Ar}), 7.46(\mathrm{~m}, 6 \mathrm{H}, \mathrm{Ar}) .{ }^{13} \mathrm{C}$ NMR $\left(\mathrm{CDCl}_{3}\right) \delta_{\mathrm{C}} 45.0,52.4,67.3,127.1,127.9,128.3,129.3,143.9,165.7$. HR MS (ESI) Calcd for $[\mathrm{M}+\mathrm{Na}]^{+} \mathrm{C}_{22} \mathrm{H}_{19} \mathrm{NONaS} 368.1080$, Found: 368.1088. HPLC [OD-H, hexane : $i$-propanole $=$ $8: 2,0.5 \mathrm{~mL} / \mathrm{min}, t_{R}[S]=15.0$ (major), $t_{R}[R]=21.2$ (minor)].

\section{Chiral Lewis Acids 7 promoted deracemization}

The chiral Lewis acid promoter 7 was generated in situ by the addition of $1 \mathrm{M}$ solution of $\mathrm{SnCl}_{4}$ in $\mathrm{CH}_{2} \mathrm{Cl}_{2}(420 \mu \mathrm{L}, 1.0$ equiv.) to the solution of $(S)$ or $(R) \alpha$-di-naphthyl-BINOL (225 mg, 0.42 mmol, 1.0 equiv.) in $\mathrm{CH}_{2} \mathrm{Cl}_{2}(10 \mathrm{~mL})$ at $0^{\circ} \mathrm{C}$ under argon atmosphere. After 15 minutes racemic azetidinone ( $0.42 \mathrm{mmol}, 1.0$ equiv.) in appropriate temperature was added. The reaction mixture was stirred for $6 \mathrm{~h}$ to $36 \mathrm{~h}$ and diluted with saturated $\mathrm{NaHCO}_{3}(10 \mathrm{~mL})$. The aqueous phase was extracted with $\mathrm{CH}_{2} \mathrm{Cl}_{2}(3 \times 20 \mathrm{~mL})$. The organic extracts were combined and dried over $\mathrm{MgSO}_{4}$. The solution was filtered and filtrate evaporated. The crude product was purified by column chromatography to yield 11a, 11d, 21a-b, 22 or 23.

(4R)- $\boldsymbol{N}$-Benzyl-4-phenylthioazetidin-2-one (21a). White solid, yield 40\%, 37\% ee, $46 \mathrm{mg}(0.17$ mmol), m.p. $129-130^{\circ} \mathrm{C}$, IR $\left(v_{\max }, \mathrm{cm}^{-1}\right): 1779(\mathrm{C}=\mathrm{O}),[\alpha]_{\mathrm{D}}{ }^{26}=+50.7\left(\mathrm{c} 0.6, \mathrm{CHCl}_{3}\right) .{ }^{1} \mathrm{H}$ NMR $\left(500 \mathrm{MHz}, \mathrm{CDCl}_{3}\right) \delta_{\mathrm{H}} 2.99\left(\mathrm{ddd}, J=14.9,2.2,1.0 \mathrm{~Hz}, 1 \mathrm{H}, \mathrm{CH}_{2}\right), 3.29(\mathrm{ddm}, J=14.9,4.9 \mathrm{~Hz}$, $\left.1 \mathrm{H}, \mathrm{CH}_{2}\right), 4.58(\mathrm{~d}, J=15.1 \mathrm{~Hz}, 1 \mathrm{H}, \mathrm{CH}-\mathrm{N}), 4.73(\mathrm{~d}, J=15.1 \mathrm{~Hz}, 1 \mathrm{H}, \mathrm{CH}-\mathrm{N}), 4.79$ (dd, $J=4.9$, $2.2 \mathrm{~Hz}, 1 \mathrm{H}, \mathrm{CH}-\mathrm{S}), 7.14$ (m, 2H, Ar), 7.32 (m, 8H, Ar). ${ }^{13} \mathrm{C} \mathrm{NMR}\left(\mathrm{CDCl}_{3}\right) \delta_{\mathrm{C}} 44.3,44.5,58.2$, 127.8, 128.4, 128.7, 128.8, 129.3, 130.4, 134.1, 135.4, 165.1. HR MS (ESI) Calcd for $[\mathrm{M}+\mathrm{Na}]^{+}$ $\mathrm{C}_{16} \mathrm{H}_{15} \mathrm{NONaS}$ 292.0767, Found: 292.0771. HPLC [OD-H, hexane : $i$-propanole $=9: 1,0.5$ $\mathrm{mL} / \mathrm{min}, t_{R}[S]=19.9$ (minor), $t_{R}[R]=23.8$ (major) $]$.

(4R)- $N$-Benzyl-4-(p-methoxyphenylthio)-azetidin-2-one (21b). White solid, yield 43\%, 21\% $e e, 54 \mathrm{mg}(0.18 \mathrm{mmol})$, m.p. $131-132^{\circ} \mathrm{C}$, IR $\left(v_{\max }, \mathrm{cm}^{-1}\right): 1776(\mathrm{C}=\mathrm{O}),[\alpha]_{\mathrm{D}}{ }^{26}=+16.7(\mathrm{c} 0.6$, $\left.\mathrm{CHCl}_{3}\right) .{ }^{1} \mathrm{H}$ NMR $\left(500 \mathrm{MHz}, \mathrm{CDCl}_{3}\right) \delta_{\mathrm{H}} 2.89\left(\mathrm{ddd}, J=15.1,2.2,1.0 \mathrm{~Hz}, 1 \mathrm{H}, \mathrm{CH}_{2}\right), 3.29$ (ddd, $J$ $\left.=15.1,4.9,1,6 \mathrm{~Hz}, 1 \mathrm{H}, \mathrm{CH}_{2}\right), 3.81\left(\mathrm{~s}, 3 \mathrm{H}, \mathrm{CH}_{3}\right), 4.58(\mathrm{~d}, J=15.1 \mathrm{~Hz}, 1 \mathrm{H}, \mathrm{CH}-\mathrm{N}), 4.73(\mathrm{~d}, J=$ $15.1 \mathrm{~Hz}, 1 \mathrm{H}, \mathrm{CH}-\mathrm{N}), 4.87$ (dd, $J=4.9,2.2 \mathrm{~Hz}, 1 \mathrm{H}, \mathrm{CH}-\mathrm{S}), 6.89$ (d, J=8,7 Hz, 2H, Ar), 7.14 (m, $2 \mathrm{H}, \mathrm{Ph}), 7.32(\mathrm{~m}, 3 \mathrm{H}, \mathrm{Ph}), 7.43(\mathrm{~d}, J=8.7 \mathrm{~Hz}, 2 \mathrm{H}, \mathrm{Ar}) .{ }^{13} \mathrm{C} \mathrm{NMR}\left(\mathrm{CDCl}_{3}\right) \delta_{\mathrm{C}} 44.8,46.5,54.5$, 56.0, 114.9, 118.2, 121.3, 126.2, 127.6, 128.1, 128.7, 130.4, 134.1, 158.4, 166.1. HR MS (ESI) Calcd for $[\mathrm{M}+\mathrm{Na}]^{+} \mathrm{C}_{17} \mathrm{H}_{17} \mathrm{NO}_{2} \mathrm{NaS}$ 322.0980, Found: 322.0976. HPLC [OD-H, hexane : $i$ propanole $=9: 1,0.5 \mathrm{~mL} / \mathrm{min}, t_{R}[S]=21.6$ (minor), $t_{R}[R]=25.8$ (major) $]$.

(6R)-3,4-Benzocepham (22). Yellow oil, yield 48\%, 46\% ee, $38 \mathrm{mg}(0.2 \mathrm{mmol}), \mathrm{IR}\left(v_{\max }, \mathrm{cm}^{-1}\right)$ : $1764(\mathrm{C}=\mathrm{O}),[\alpha]_{\mathrm{D}}{ }^{26}=+20.2\left(\mathrm{c} 0.41, \mathrm{CHCl}_{3}\right) .{ }^{1} \mathrm{H} \mathrm{NMR}\left(500 \mathrm{MHz}, \mathrm{CDCl}_{3}\right) \delta_{\mathrm{H}} 2.97(\mathrm{dm}, J=14.8$ $\left.\mathrm{Hz}, 1 \mathrm{H}, \mathrm{CH}_{2}\right), 3.51$ (ddm, $J=14.8,4.1 \mathrm{~Hz}, 1 \mathrm{H}, \mathrm{CH}_{2}$ ), 4.25 (d, $\left.J=16.6 \mathrm{~Hz}, 1 \mathrm{H}, \mathrm{CH}-\mathrm{N}\right), 4.79$ (d, $J=16.6 \mathrm{~Hz}, 1 \mathrm{H}, \mathrm{CH}-\mathrm{N}), 4.81$ (dm, $J=4.1 \mathrm{~Hz}, 1 \mathrm{H}, \mathrm{CH}-\mathrm{S}), 7.17$ (m, 3H, Ar), 7.24 (m, 1H, Ar). 
${ }^{13} \mathrm{C}$ NMR $\left(\mathrm{CDCl}_{3}\right) \delta_{\mathrm{C}} 42.1,45.9,49.1,126.2,127.7,128.3,128.4,129.5,130.0,166.6$. HR MS (ESI) Calcd for $[\mathrm{M}+\mathrm{Na}]^{+} \mathrm{C}_{10} \mathrm{H}_{9} \mathrm{NONaS}$ 214.0297, Found: 214.0288. HPLC [OD-H, hexane : $i$ propanole $=9: 1,1.0 \mathrm{~mL} / \mathrm{min}, t_{R}[R]=20.9$ (major), $t_{R}[S]=25.5$ (minor) $]$.

(6R)-3-Methylene-5-oxacepham (23). Yield 48\%, 22\% ee, $28 \mathrm{mg}(0.2 \mathrm{mmol}),[\alpha]_{\mathrm{D}}{ }^{26}=+9.2(\mathrm{c}$ $0.8, \mathrm{CHCl}_{3}$ ). HPLC $\left[\mathrm{AD}-\mathrm{H}\right.$, hexane $: i$-propanole $=95: 5,1.0 \mathrm{~mL} / \mathrm{min}, t_{R}[R]=14.9$ (major), $t_{R}[S]=20.7$ (minor) $]$.

\section{Assay of DD-carboxypeptidase activity}

The enzyme activity was measured as decribed previously.154,153 Samples for assay of the DDcarboxypeptidase activity consisted of $10 \mu \mathrm{L}$ of DD-carboxypeptidase from Saccharopolyspora erytraea PZH TZ 64-575 (40 units/mg), $20 \mu \mathrm{L}$ of substrate solution containing $4.52 \mathrm{mg} / \mathrm{mL} N \alpha$, $N \varepsilon$-diacetyl-L-lysyl-D-alanyl-D-alanine in $0.1 \mathrm{M}$ phosphate buffer, $\mathrm{pH} 8.0$ and $10 \mu \mathrm{L}$ of $0.1 \mathrm{M}$ phosphate buffer, $\mathrm{pH}$ 8.0. A standard sample containing $20 \mu \mathrm{L}$ of D-alanine in distilled water. The reaction mixture for assay of the DD-carboxypeptidase activity consisted of $60 \mu \mathrm{L}$ of 0.05 $\mathrm{mg} / \mathrm{mL}$ flavin adenine dinucleotide in $0.1 \mathrm{M}$ phosphate buffer, $\mathrm{pH} 8.0,10 \mu \mathrm{L}$ of $0.05 \mathrm{mg} / \mathrm{mL}$ horseradish peroxidase (1230 units $/ \mathrm{mg}$ ) in distilled water, $5.0 \mu \mathrm{L}$ of $5.0 \mathrm{mg} / \mathrm{mL} o$-dianisidine in methanol, and $2.0 \mu \mathrm{L}$ of $11.77 \mathrm{mg} / \mathrm{mL}$ D-amino acid oxidase from procine kidney (6.7 units $/ \mathrm{mg}$ ) in $0.1 \mathrm{M}$ phosphate buffer, $\mathrm{pH}$ 8.0. Samples were incubated for 30 minutes at $37{ }^{\circ} \mathrm{C}$ and than boiled for 2 minutes. After cooling, $77 \mu \mathrm{L}$ of the reaction mixture was added, and all samples were incubated for 10 minutes at $37^{\circ} \mathrm{C}$. Next, was added $350 \mu \mathrm{L}$ to each sample of a mixture consisting of $\mathrm{MeOH}$, distilled water and sulfuric acid ( $5: 5: 6$ by volume). Extinction of the resulting solution was measured at $540 \mathrm{~nm}$. The inhibition of DD-peptidase $64-575$ by the discussed compounds was evaluated. Mixtures of $10 \mu \mathrm{L}$ of DD-peptidase 64-575 (40 units $/ \mathrm{mg}$ ), $5.0 \mu \mathrm{L}$ of $0.1 \mathrm{M}$ phosphate buffer, $\mathrm{pH} 8.0$ were incubated for 45 minutes at $37{ }^{\circ} \mathrm{C}$. The concentration of tested compounds in the mixture was from 0.04 to $0.0001 \mathrm{M}$. following the incubation, $20 \mu \mathrm{L}$ of substrate solution was added to $20 \mu \mathrm{L}$ of each sample and the resulting mixtures were incubated again.

\section{Assay of $\beta$-lactamase activity}

The inhibition of penicillinase was evaluated following a literature method. The sample for assay of inhibition of $\beta$-lactamase consisted of $10 \mu \mathrm{L}$ of penicillinase (Penase, $5 \times 106 \mathrm{IU} / \mathrm{mL}$, Bacto), 20 $\mu \mathrm{L} 0.1 \mathrm{M}$ phosphate buffer, $\mathrm{pH} 7.0,10 \mu \mathrm{L}$ solution of tested compound in methanol. The samples were incubated for 30 minutes at $37^{\circ} \mathrm{C}$, than $30 \mu \mathrm{L}$ of nitrocephin, $430 \mu \mathrm{L} 0.1 \mathrm{M}$ phosphate buffer $\mathrm{pH} 7.0$ were added and all samples were incubated for 10 minutes at $37^{\circ} \mathrm{C}$. Absorption was measured at $428 \mathrm{~nm}$.

\section{Acknowledgements}

This work was supported by the Ministry of Education and Science, grant N N204 192738. Anna Kozioł thanks the President of Polish Academy of Sciences for a doctoral fellowship. 


\section{References}

1. (a) Morin, R. B.; Gorman, M. Chemistry and Biology of $\beta$-Lactam Antibiotics; Academic: New York, 1982; Vol. 1-3. (b) Bruggink, A. Synthesis of $\beta$-Lactam Antibiotics; Kluwer: Dordrecht, Netherlands, 2001.

2. Shah, S. K.; Dorn, C. P.; Finke, P. E.; Hale, J. J.; Hagmann, W. K.; Brause, K. A.; Chandler, G. O.; Kissinger, A. L.; Ashe, B. M.; Weston, H.; Knight, W. B.; Maycock, A. L.; Dellea, P. S.; Fletcher, D. S.; Hand, K. M.; Mumford, R. A.; Underwood, D. J.; Doherty, J. B. J. Med. Chem. 1992, 35, 3745.

3. Han, W. T.; Trehan, A. K.; Wright, J. J. K.; Federici, M. E.; Seiler, S. M.; Meanwell, N. A. Bioorg. Med. Chem. 1995, 3, 1123.

4. (a) Borthwick, A. D.; Weingarten, G.; Haley, T. M.; Tomaszewski, M.; Wang, W.; Hu, Z.; Bedard, J.; Jin, H.; Yuen, L.; Mansour, T. S. Bioorg. Med. Chem. Lett. 1998, 8, 365. (b) Deziel, R.; Malenfant, B. Bioorg. Med. Chem. Lett. 1998, 8, 143. (c) Yoakim, C.; Ogilvie, W.W.; Cameron, D.R.; Chabot, C.; Guse, I.; Hache, B.; Naud, J.; O’Meara, J.A.; Plante, R.; Deziel, R. J. Med. Chem. 1998, 41, 2882. (d) Ogilvie, W. W.; Yoakim, C.; Do, F.; Hache, B.; Lagace, L.; Naud, J.; O’Meara, J.A.; Deziel, R. Bioorg. Med. Chem. 1999, 7, 1521. (e) Bonneau, P. R.; Hasani, F.; Plouffe, C.; Malenfant, E.; LaPlane, S. R.; Guse, I.; Ogilvie, W.W.; Plante, R.; Dvidson, W. C.; Hopkins, J. L.; Morelock, M. M.; Cordingley, M. G.; Deziel, R. J. Am. Chem. Soc. 1999, 121, 2965.

5. Rosenblum, S. B. In The Art of Drug Synthesis; Johnson, D. S.; Li, J. J. Eds.; Wiley: Hoboken, 2007, Chapter 13, p 183.

6. (a)Wild, H. In The Organic Chemistry of $\beta$-Lactams; Georg, G. I. Eds.; VCH Publishers: Weinheim, 1993; p 49. (b) Ojima, I. Acc. Chem. Res., 1995, 28, 383. (c) Ojima, I.; Delaloge, F. Chem. Soc. Rev. 1997, 26, 377; (d) Singh, G. S. Tetrahedron 2003, 59, 7631. (e) Palomo, C.; Aizpurua, J. M.; Ganboa, I.; Oiarbide, M. Curr. Med. Chem. 2004, 11, 1837. (f) Fisher, J. F.; Meroueh, S. O.; Mobashery, S. Chem. Rev.2005, 105, 395. (g) Alcaide, B.; Almendros, P.; Aragoncillo, C. Chem. Rev. 2007, 107, 4437. (h) D'hooghe, M.; Dekeukeleire, S.; Leemans, E.; De Kimpe, N. Pure Appl. Chem., 2010, 82, 1749.

7. Kozioł, A.; Furman, B.; Frelek, J.; Woźnica, M.; Altieri, E.; Chmielewski, M. J. Org. Chem. 2009, 74, 5687.

8. Nagaraja, S.R.; More O'Ferral, R. A. J. Am. Chem. Soc. 1990, 112, 2729.

9. Kozioł, A.; Frelek, J.; Woźnica, M.; Furman, B.; Chmielewski, M. Eur. J. Org. Chem. 2009, 338.

10. Veysoglu T.; Mitscher L. A.; Swayze J. K. Synthesis, 1980, 807.

11. Kałuża, Z.; Kazimierski, A.; Lewandowski, K.; Suwińska, K.; Szczęsna, B.; Chmielewski, M. Tetrahedron 2003, 59, 5893.

12. Knox, J. R.; Moews, P. C., J. Mol. Biol. 1991, 220, 435. 
13. a) Kurzatkowski, W.; Solecka, J.; Filipek, J.; Kurzatkowski, J. D.; Kurylowicz, W. Appl. Microbiol. Biotechnol. 1990, 33, 452; b) Rohl, F.; Rabenhorst, J.; Zahner, H. Arch. Microbiol. 1987, 147, 315. 